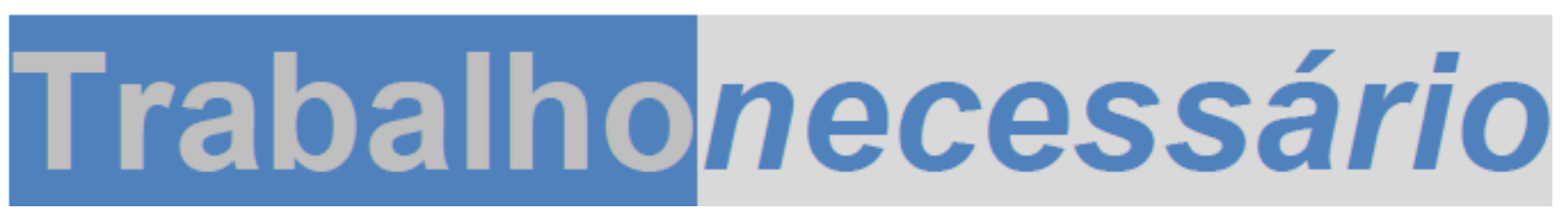

\author{
Issn: 1808 - 799X \\ ano 11, no $16-2013$
}

\title{
HEGEMONIA, CAPITAL-IMPERIALISMO E INTELECTUAIS: categorias marxistas para um esforço de análise da relação democracia-educação
}

\author{
Carlos Eduardo Rebuá Oliveira ${ }^{1}$
}

\begin{abstract}
Resumo: O artigo objetiva debater a relação democracia e educação partindo de três eixos analíticos fundamentais, quais sejam os vínculos dialéticos entre hegemonia e educação, o conceito de capital-imperialismo e o de intelectuais. Temos clareza da amplitude da temática escolhida e por isso optamos por lastrear nossas considerações nas categorias marxistas acima citadas. Antonio Gramsci representa nossa referência fundamental, num "debate" que, ainda que sucinto, obviamente não pode prescindir de Marx, Lênin, Trotsky e outros mais. A escolha do tema "democracia e educação", bastante atual e pertinente, se apresenta cada vez mais como questão basilar para todos (as) aqueles (as) que não enxergam de maneira dicotomizada tal relação e que buscam, na tessitura do real, forjar um mundo efetivamente democrático e uma educação realmente de todos.
\end{abstract}

Palavras-Chave: hegemonia; capital-imperialismo; intelectuais

\begin{abstract}
The purpose of this article is to discuss the democratic and education links from the basic analytic three axles, such as the dialectic bonds between hegemony and education, and the concepts of imperialism-capital and intelectuals. We are sure of the extent of the chosen theme and therefore we have decided to state our comments on the mentioned Marxist categories. Antonio Gramsci is our main reference in a "discussion" that, besides being concise, cannot do without Marx, Lênin, Trotsky and many others. The selection of the theme "democracy and education", very pertinent and actual, is more and more a basic question for all the ones who do not see such relation as a "divided" one and in fact search for, a way to build a world really democratic and education for everyone.
\end{abstract}

Key-words: hegemony; imperialism-capital; intellectuals.

\footnotetext{
${ }^{1}$ Doutorando em Educação pelo Programa de Pós-Graduação em Educação da Universidade Federal Fluminense (PPGE/UFF). Bolsista da Coordenação de Aperfeiçoamento de Pessoal de Nível Superior (CAPES). Membro do Núcleo de Estudos e Pesquisas em Filosofia, Política e Educação da Universidade Federal Fluminense (NUFIPE). E-mail: eduardorebua@yahoo.com.br
}

TrabalhoNecessário - www.uff.br/trabalhonecessario; Ano 11, № 16/2013. 


\section{Trabalhonecessário}

Issn: 1808 - 799X

ano $11, \mathrm{n}=16-2013$

Quando os dominadores falarem falarão também os dominados.

Quem reconhece a situação como pode calar-se?

(...)

(Bertolt Brecht, O elogio da dialética)

Para tornar mais articuladas e coerentes, em termos teórico-metodológicos, as três categorias que escolhemos para estas considerações, optamos por construir um "alicerce autoral" centrado nas contribuições de Antonio Gramsci, autor que nos acompanha em nossas investigações acadêmicas. Em síntese, os três elementos que nos parecem muito caros para a temática "democracia e educação são: (i) a relação dialética entre hegemonia e educação; (ii) o capitalimperialismo e a teoria do desenvolvimento desigual e combinado (que para nós não podem ser abordados separadamente) e (iii) os intelectuais.

Compreendemos que tais questões alinhavam leituras realizadas por nós e permitem construir uma abordagem que vai do macro ao micro, ou da totalidade à particularidade, partindo da hegemonia e suas dimensões à atuação teórica e prática dos intelectuais, tendo como lastro (político, econômico, cultural, espacial) o conceito de capital-imperialismo e a teoria do desenvolvimento desigual e combinado.

Na teoria de Antonio Gramsci (1891-1937), que segundo Eric Hobsbawm representa o pensamento mais original surgido no Ocidente desde 1917 (2011, p. 287), hegemonia e educação se vinculam de maneira dialética, sendo toda relação pedagógica uma relação hegemônica, assim como qualquer relação hegemônica é necessariamente pedagógica (JESUS, 1989, pp. 122-123). Rummert, Algebaile e Ventura (2011, p. 14) abordam tal questão ao frisarem o caráter pedagógico de toda hegemonia, que em Gramsci corresponde à liderança cultural e ideológica de uma classe sobre as demais, pressupondo a capacidade de um bloco histórico (aliança de classes e frações de classes, duradoura e 


\section{Trabalhonecessário}

Issn: 1808 - 799X

ano 11, no $16-2013$

ampla) dirigir moral e culturalmente, de forma sustentada, toda a sociedade (MORAES, 2009, p. 35).

Sobre a primeira afirmativa (toda relação pedagógica é uma relação hegemônica), Antonio Tavares de Jesus (op. cit., p. 19) diz que a educação representa um processo para a concretização de uma concepção de mundo (ideologia), cuja importância é fundamental tanto na preservação de uma hegemonia, quanto na sua renovação (contra-hegemonia). A educação pode agir tanto como instrumento de dissimulação a serviço das classes dominantes, como também pode explicitar para os dominados as contradições existentes, permitindo-Ihes "reagir a todas elas e tentar a contra-hegemonia" (p. 60).

Em relação à segunda afirmativa (as relações hegemônicas como pedagógicas), Jesus pontua que "tanto a hegemonia como a contra-hegemonia exigem um desempenho pedagógico mantenedor-reformador da relação total de poder, de acordo com a situação histórica" (Ibidem). A natureza pedagógica das relações hegemônicas se confirma teoricamente pelo próprio significado de hegemonia desenvolvido por Gramsci: direção intelectual/moral e dominação, exercida por uma classe sobre as demais, através da sociedade política (Estado strictu sensu) e da sociedade civil (espaço dos aparelhos privados de hegemonia), dialeticamente ligadas. $\mathrm{Na}$ prática, esta natureza pedagógica também é confirmada, uma vez que somente uma ação pedagógica é capaz de forjar uma nova cultura (através da imperiosa reforma intelectual e moral, como preconizava o revolucionário sardo) sintonizada com os objetivos da nova classe hegemônica, e é capaz de transformar concepções de mundo norteadas pela superstição e pelo folclore, em concepções de mundo histórico-críticas (p. 72). Diz Gramsci (2006, p. 399):

(...) Mas a relação pedagógica não pode ser limitada às relações especificamente 'escolares', através das quais as novas gerações entram em contato com as antigas e absorvem suas experiências e seus valores historicamente necessários, 'amadurecendo' e desenvolvendo uma personalidade própria, histórica e culturalmente superior. Esta relação

TrabalhoNecessário - www.uff.br/trabalhonecessario; Ano 11, № 16/2013. 


\section{Trabalhonecessário}

Issn: 1808 - 799X

ano 11, no $16-2013$

existe em toda a sociedade no seu conjunto e em todo indivíduo com relação aos outros indivíduos, entre camadas intelectuais e não intelectuais, entre governantes e governados, entre elites e seguidores, entre dirigentes e dirigidos, entre vanguardas e corpos de exército. Toda relação de 'hegemonia' é necessariamente uma relação pedagógica, que se verifica não apenas no interior de uma nação, entre as diversas forças que a compõem, mas em todo o campo internacional e mundial, entre conjuntos de civilizações nacionais e continentais.

É fundamental frisar, a partir do que expomos anteriormente, que é impossível pensar a hegemonia - em termos gramscianos - sem pensar na luta de classes. Abordar a hegemonia e a contra-hegemonia ${ }^{2}$ significa tocar na questão do antagonismo entre as classes sociais que, a partir de sua posição (dominante ou subalterna, no interior da sociedade e do Estado), exercem/sofrem/disputam o poder de maneira permanente (DANTAS, 2008, p. 91). Assim, entendemos que para se tratar do tema "democracia e educação" é imprescindível o "chão" do materialismo histórico-dialético, que compreende a História como processo (e não como determinismo) e o desenvolvimento das

${ }^{2}$ O conceito de contra-hegemonia não foi criado por Gramsci, correspondendo a uma interpretação do conceito de hegemonia do filósofo revolucionário a partir de uma perspectiva crítica, atualizada e, sobretudo estratégica, por parte de inúmeros marxistas ${ }^{2}$, objetivando traduzir e/ou demarcar, em termos de luta ideológica e material, um projeto antagônico de classe, em relação à hegemonia burguesa. O termo, que se consolidou pelo uso, significa que a luta é contra uma hegemonia estabelecida, uma luta que objetiva a construção de uma nova hegemonia, e que por isso, corresponde a um projeto de classe distinto. Como corresponde a uma interpretação, tal conceito oferece muitas dificuldades para quem se dispõe a explorar seu (s) significado (s). Além de escassa na literatura marxista, a definição do conceito pode ser encontrada sob os mais distintos espectros político-ideológicos. Não se trata de incorporar um neologismo, mas de utilizar um conceito legitimado por diversos intelectuais importantes dentro do campo marxista (ainda que poucos o definam), que fazem uso da "contra-hegemonia" querendo apontar para outro projeto de classe, outro mundo possível. Para Eduardo Granja Coutinho (2008, p. 77), parafraseando Marx, é possível dizer que toda hegemonia traz em si o germe da contra-hegemonia, existindo uma unidade dialética entre ambas, com uma se definindo pela outra. Raymond Williams (1979, pp. 115-116), frisa que a hegemonia sofre uma resistência continuada, limitada, alterada e desafiada por pressões que não são as suas próprias. Com isso, é preciso acrescentar a este conceito outro: "contra-hegemonia" (e/ou "hegemonia alternativa"), elementos reais e persistentes na prática. Daniel Campione (2003, p. 53) também utiliza a expressão "hegemonia alternativa" como sinônimo de contra-hegemonia, afirmando que só é possível a conversão dos grupos dominados em hegemônicos se estes passarem do plano econômico-corporativo ao plano ético-político (com o vetor "ético" indicando a dimensão intelectual e moral e o vetor "político" o controle do aparato de Estado). Por sua vez, Terry Eagleton (1997, p. 107) afirma que todo poder governante é forçado a enfrentar forças contra-hegemônicas, parcialmente constitutivas de seu próprio domínio. 


\section{Trabalhonecessário}

Issn: 1808 - 799X

ano $11, \mathrm{n}=16-2013$

relações de produção e das forças produtivas como algo profundamente marcado pelo embate entre as classes, que tendem a conformar "hegemonias" e "contrahegemonias", que por sua vez compreendem - dialeticamente - não apenas uma dimensão material, mas também uma dimensão simbólica.

Da mesma forma que Gramsci, a partir de sua discussão sobre hegemonia, nos ajuda a pensar a dialética dominância-subalternidade na relação entre as classes (conforme exposto acima), também nos oferece um suporte teóricometodológico para pensarmos a hegemonia numa perspectiva mais ampla, qual seja a da relação entre sociedades/Estados, um dos focos da análise de Rummert, Algebaile e Ventura (2011), que encontra em Fontes (2010) e seu conceito de "capital-imperialismo" um pilar fundamental.

Ampliando o conceito de imperialismo em Lênin (assim como Gramsci ampliou a abordagem leniniana acerca da hegemonia), e tendo obviamente em Marx e Gramsci outras duas referências fundamentais, Fontes almeja capturar o movimento histórico do capital (FONTES, op. cit., p. 11), radiografando sua expansão voraz e cada vez mais complexa em termos estruturais e superestruturais, na contemporaneidade. Partindo de nossa exposição anterior sobre hegemonia, onde enfatizamos que em Gramsci o vetor-cultural (consenso) da dominação de classe tem atenção especial, entendemos como de suma importância a abordagem da autora marxista, que ao tratar dos novos vínculos entre a expansão do capitalismo e o imperialismo - sob o conceito de capitalimperialismo -, enfatiza a dimensão econômica da hegemonia (fundamentalmente o vetor-força da dominação de classe, junto à coerção propriamente dita), dialeticamente vinculada às outras (dimensões política, cultural, pedagógica, etc.; correspondentes ao vetor-consenso da hegemonia de classe). Rummert, Algebaile e Ventura (op. cit., p. 3) sublinham os traços mais importantes do capital-imperialismo, analisado por Fontes: "predomínio do capital monetário; a 


\section{Trabalhonecessário}

Issn: 1808 - 799X

ano 11, no $16-2013$

dominação pura da propriedade capitalista e seu impulso avassaladoramente expropriador".

Para Fontes (2010, p. 13), "a ideia de capital-imperialismo procura recuperar os conceitos clássicos para explorar um presente forçosamente diverso do período no qual nasceram, mas que representa a continuidade e o aprofundamento da mesma dinâmica do capital." E neste presente, é fundamental que se analise os "papéis periféricos" de países que, na dinâmica complexa, multifacetada do capital em seu processo de reprodução sócio-metabólica (MÉSZÁROS, 2011), se integram de maneira subalterna ao capital-imperialismo, como apontam Rummert, Algebaile e Ventura, sob características "ornitorrincas" (OLIVEIRA, 2003), onde o moderno e o arcaico estão umbilicalmente ligados.

Desta forma, pensar em democracia e educação na realidade hodierna brasileira - temas profundamente amplos e marcados por tensões diversas significa, sob o prisma do marxismo, compreender a inserção do Brasil ao capitalimperialismo, contextualizando seu "lugar" a nível internacional, sem desconsiderar suas dinâmicas internas. Rummert, Algebaile e Ventura (op. cit., p. 13) apresentam especificidades ${ }^{3}$ da retardatária terra brasilis, que a coloca num patamar ao mesmo tempo "acima e abaixo", ou seja, dominante (em relação a outros países ditos "não-emergentes - na América Latina, sobretudo) e subalterno (em relação ao núcleo orgânico do capital). Em outras palavras, é impossível pensar/debater a educação brasileira nos dias atuais (assim como em todo seu processo de gestação e desenvolvimento histórico) - em relação à cidadania, democracia, limites, possibilidades, etc., sem articular as contradições internas da dominação burguesa-capitalista com as contradições "maiores" do capitalimperialismo a nível global (FONTES, op. cit., p. 15).

\footnotetext{
${ }^{3}$ São eles: um forte ciclo de industrialização, onde diferentes setores se entrelaçam; um Estado robusto, "plasticamente adaptado ao fulcro central da acumulação de capitais", além de formas estáveis de contenção e domesticação dos trabalhadores; a complexificação de nosso padrão de sociabilidade, aprofundada pelas contradições resultantes do longo processo de colonização, nãoapagadas no período pós-colonial.
}

TrabalhoNecessário - www.uff.br/trabalhonecessario; Ano 11, № 16/2013. 


\section{Trabalhonecessário}

Issn: 1808 - 799X

ano 11, no $16-2013$

Concordamos com Rummert, Algebaile e Ventura que na análise do capital-imperialismo é condição fundamental recuperarmos a teoria do desenvolvimento desigual e combinado ${ }^{4}$ - debatida por Oliveira (2003) ao analisar a "razão dualista" -, que encontra em Trotsky uma referência fundamental. De acordo com Michael Löwy, tal teoria - que para o economista belga Ernest Mandel, corresponde à principal contribuição de Trotsky ao marxismo - tem sua importância não apenas porque contribui bastante para a análise do imperialismo, mas também porque rompe com o evolucionismo, com a ideia de progresso linear e com o eurocentrismo. Nesta teoria o revolucionário russo busca explicar o desenvolvimento de diferentes formações econômico-sociais em seu desenvolvimento histórico, tentando compreender as contradições dos chamados "países periféricos" do capitalismo, ligados entre si e aos "países centrais" pelo modo de produção e pelo comércio. Trotsky buscava compreender o desenvolvimento do capitalismo partindo do processo de inserção da economia russa ao sistema, numa análise que compreendia as dimensões econômica, social e cultural e entendia como elementos não-antagônicos a existência de formas de produção/reprodução da vida arcaicas (o agricultor "primitivo" das florestas russas) e modernas (o operário russo dos grandes centros urbanos, de industrialização concentrada).

Nas palavras de Löwy (2000, p. 162):

Estes diferentes estágios não estão simplesmente um ao lado do outro, numa espécie de coexistência congelada, mas se articulam, se combinam, "se amalgamam": o processo do desenvolvimento capitalista, criado pela união das condições locais (atrasadas) com as condições gerais (avançadas) cria "um amálgama social cuja natureza não pode ser definida pela busca de lugares comuns históricos, mas somente por meio de uma análise com base materialista".

\footnotetext{
${ }^{4}$ Definida por Rummert, Algebaile e Ventura (op. cit., p. 33) como "uma manifestação do modo de produção capitalista".
}

TrabalhoNecessário - www.uff.br/trabalhonecessario; Ano 11, № 16/2013. 


\section{Trabalhonecessário}

Issn: 1808 - 799X

ano $11, \mathrm{n}=16-2013$

Assim, debruçar-se sobre as questões concernentes à democracia e educação, seja no Brasil ou em Uganda, requer uma análise que articule dialeticamente o local e o global, estando atento às especificidades de cada país e tendo como lastro fundamental os processos contínuos, porém instáveis e contraditórios, de construção da hegemonia burguesa (nacional e internacionalmente), forjada de maneira desigual, porém combinada, tendo no capital-imperialismo sua pedra de toque fundamental.

Retomando a contribuição de Gramsci acerca da hegemonia, é imperioso explicitar que na construção de qualquer hegemonia, entendida como o somatório dialético ${ }^{5}$ domínio (força) + direção (consenso), é fundamental a atuação dos intelectuais, mediadores, organizadores e produtores de capital simbólico, como afirma Vieira (2008), em seu esforço de síntese da concepção de intelectual em três pensadores de referência: Mannheim, Gramsci e Bourdieu. Dos três autores, nos interessa, conforme já dito, a contribuição do revolucionário Antonio Gramsci. Se os conceitos de hegemonia e sociedade civil notabilizaram Gramsci como um dos mais importantes interlocutores de Marx, foi a discussão à respeito dos intelectuais que conferiu à sua obra um profundo caráter de originalidade. Presente de maneira não-sistematizada em Marx, Engels e Lênin, a questão dos intelectuais será estudada com profundidade em Gramsci, oferecendo novos e importantes elementos teóricos ao marxismo.

Para Gramsci, não existe uma classe autônoma, independente, de intelectuais: cada modo de produção possui uma classe fundamental, que por sua vez possui sua própria camada de intelectuais ou tende a construí-la. Segundo ele, os intelectuais são, ao mesmo tempo, dirigentes, sábios, organizadores e educadores.

\footnotetext{
${ }^{5}$ Não como um jogo de soma cujo resultado é zero: $80 \%$ de coerção significa $20 \%$ de consenso!

TrabalhoNecessário - www.uff.br/trabalhonecessario; Ano 11, № 16/2013.
} 


\section{Trabalhonecessário}

Issn: 1808 - 799X

ano 11, no $16-2013$

Rompendo com leituras elitistas da realidade social, inclusive dentro do próprio marxismo, Gramsci vai defender que todos os homens são intelectuais ${ }^{6}$ : não existe atividade humana que seja unicamente manual; não existe indivíduo que não pense o mundo, que não interprete/interpele a realidade, que não participe de uma concepção de mundo. Não existem não-intelectuais, mas tipos distintos de intelectuais.

Se todos os homens são intelectuais, nem todos desempenham na sociedade a função de intelectuais (GRAMSCI, 2010, p. 18). No entanto, desempenhar diferentes funções intelectuais, diz Semeraro (2006, p. 138), não deve justificar hierarquias tampouco divisão de classes na sociedade. Assim como fez com o conceito de hegemonia, Gramsci amplia ${ }^{7}$ também a concepção do intelectual e a importância que ele dedica a este grupo social, tem relação direta com seu modo de conceber a hegemonia: a articulação dialética da força com o consenso, sendo este o "campo" de atuação dos intelectuais.

Vieira $(2008$, p. 77$)$ sintetiza as concepções de intelectual ${ }^{8}$ em Gramsci, quando diz que:

(...) o conceito de intelectual nos textos de Gramsci reúne, no mínimo, três sentidos principais: o intelectual tradicional, que despreza o sentimento popular e organiza-se como casta; o orgânico ao projeto do Estado burguês, que produz as condições ideológicas para a exploração dos trabalhadores pelo capitalismo; e o intelectual orgânico aos interesses das classes subalternas, que visa a organização de uma nova forma de domínio e de direção política.

$\mathrm{Na}$ obra de Gramsci, os intelectuais são identificados como: "representantes da hegemonia", como "funcionários da superestrutura". Os

\footnotetext{
${ }^{6}$ É comum encontrar, a respeito desta opinião de Gramsci, o termo "filósofos", ao invés de "intelectuais".

${ }^{7}$ "Eu amplio muito a noção de intelectual, não me limitando à noção corrente que se refere aos grandes intelectuais... Justamente na sociedade civil operam os intelectuais" (GRAMSCI apud SEMERARO, 2006, pp. 147-148).

${ }^{8}$ Por questão de espaço, não analisaremos de forma pormenorizada as distintas concepções de intelectual em Gramsci.
} 


\section{Trabalhonecessário}

Issn: 1808 - 799X

ano 11, no $16-2013$

intelectuais não são as classes propriamente, mas grupos que se vinculam às distintas classes ${ }^{9}$ e que representam a hegemonia, orquestrando o consenso, soldando estrutura e superestrutura, elaborando a ideologia dos grupos ao qual se vinculam e a transformando em "concepção de mundo", que adere a todo corpo social. Desta forma, os intelectuais são fundamentais para a hegemonia de uma classe.

Os intelectuais são agentes da sociedade política e da sociedade civil ${ }^{10} . \mathrm{Na}$ primeira, gerem o Estado e a força armada; na última, estimulam e desenvolvem as ideologias das classes ao qual estão ligados, nos aparelhos privados de hegemonia ${ }^{11}$ : Igreja, escolas, partidos, meios de comunicação, etc.

É importante frisar que os aparelhos privados de hegemonia não são monopólio da classe dominante que a exerce: as classes dominadas que também desejam conquistá-la, segundo Gramsci, ocupam espaços dentro do aparelho que permitem a construção de "trincheiras" e logo, de uma guerra de posição ${ }^{12} . \mathrm{Na}$

\footnotetext{
9 Todas as categorias de intelectuais que Gramsci distinguiu têm em comum o fato de se vincularem, em menor ou em maio grau, a uma classe determinada (PORTELLI, 1977, p. 105).

${ }^{10}$ Para Gramsci, que diferentemente de Marx vivenciou as profundas mudanças na relação entre economia e política no século XX (LIGUORI, 2007, pp. 47-48), o Estado, lugar de uma hegemonia de classe, não se resume à sociedade política (aparato político-jurídico - o espaço da coerção) apenas, mas compreende também, numa perspectiva de "Estado ampliado" (que se contrapõe à visão de Marx e Engels, que entendiam o Estado como "restrito") e numa concepção dialética da realidade histórico-social, a sociedade civil (locus dos aparelhos privados de hegemonia, como a Igreja, a escola e a mídia - o espaço da hegemonia, do consenso).

${ }^{11}$ Os aparelhos privados de hegemonia são as organizações materiais que compõem a sociedade civil moderna, como por exemplo, a escola, a Igreja, os partidos políticos, as associações privadas, os meios de comunicação, a Universidade, os sindicatos, as organizações nãogovernamentais. Estes aparelhos forjam, reproduzem e legitimam interesses de classe, "educando" ideológica e culturalmente as diversas classes e frações de classe da sociedade civil. São chamados de "privados" porque a adesão a eles é voluntária e para distingui-los da esfera pública do Estado.

${ }_{12}$ Em sua leitura da hegemonia, Gramsci defendia a existência dois tipos de embate político: a guerra de posição (conquista da hegemonia civil) e a guerra de movimento (revolução permanente), estratégias específicas para condições da luta de classes específicas. A primeira se daria em países onde a sociedade civil estivesse estruturada (sociedades de "Estado ampliado" - Brasil de hoje, por exemplo) e se constituiria numa "guerra de trincheiras", com recuos e avanços, através dos aparelhos privados de hegemonia, buscando conquistar posições de direção e governo dentro da sociedade. Já a segunda seria a forma possível nos países de frágil sociedade civil (sociedades de "Estado restrito" - a Rússia pré-Revolução de Outubro, por
} 


\section{Trabalhonecessário}

Issn: 1808 - 799X

ano 11, no $16-2013$

escola - que segundo Gramsci, é o principal organismo, na sociedade civil, de formação de intelectuais ${ }^{13}$ - os educadores, também intelectuais (pois desenvolvem a cultura, o conhecimento), desempenham função primordial no tocante à construção/manutenção da hegemonia da classe ao qual se vincula.

De todos os aparelhos privados de hegemonia, sem dúvida a escola representa um dos mais importantes na construção/difusão de consensos. É perfeitamente possível encontrar uma pessoa que não tenha religião, que não integre uma instituição religiosa, bem como alguém que não seja filiado a um partido político ou associado a um sindicato. No entanto, é bastante difícil alguém não ter frequentado a escola em algum momento de sua existência.

O comunista italiano vai se preocupar em discutir a organização da escola, uma vez que a considera uma das mais destacadas instituições que movimentam as ideologias que circulam na sociedade civil, legitimando as ideias dos grupos dominantes ou enfrentando-as, com o objetivo de criar uma nova sociedade ${ }^{14}$. Gramsci preocupava-se profundamente com a formação de novos intelectuais, organicamente vinculados aos "de baixo". Tais intelectuais deveriam, dentre outras funções, tornar mais organizados os problemas destes grupos subalternos, para então ser possível a construção de um novo bloco cultural e social, de uma reforma intelectual e moral (SOARES, 2000, p. 191).

Fontes (op. cit., p. 14) afirma que atualmente, "violência e convencimento seguem conjugados". Conforme dito anteriormente, na construção do consenso, os intelectuais e suas ferramentas (Alves, 2010, p. 161) desempenham papel

exemplo), correspondendo a uma irrupção rápida e violenta contra o Estado. Os dois tipos de guerra não se restringem apenas ao movimento de tomada do poder (conquistar o Estado), mas também dizem respeito à luta política, ou seja, o processo que antecede a tomada do poder; e também à construção de uma nova ordem, ou seja, o "depois" da conquista do poder.

${ }^{13}$ Semeraro salienta que para a tarefa de formação de intelectuais, além da escola, também contribuem "o partido, a fábrica, a igreja, a atividade política, a participação nas organizações, nos movimentos sociais e culturais etc." (2006, p. 139).

${ }^{14}$ Para Antônio Tavares de Jesus, "um dos aspectos essenciais da sociedade civil é o de criar e difundir os elementos que compõem a estrutura ideológica - entre os quais o principal deles, a escola - como instrumentos de hegemonia" (1989, p. 55).

TrabalhoNecessário - www.uff.br/trabalhonecessario; Ano 11, № 16/2013. 


\title{
Trabalhonecessário
}

Issn: 1808 - 799X

ano $11, \mathrm{n}=16-2013$

central, sejam eles orgânicos aos "de cima" ou aos "de baixo". Ao se debater democracia e educação, os intelectuais vinculados às lutas dos subalternos e, por isso, cientes do embate entre as classes sociais, devem organizar consensos contra-hegemônicos, dentre outras formas, partindo de duas perguntas basilares: democracia para quem? educação para quem?

Se Coutinho (1979), em fins dos anos 1970, defendeu a democracia como valor universal ${ }^{15}$, num texto com este mesmo título, sendo alvo de pesadas críticas à esquerda e à direita, anos mais tarde, em famosa entrevista à Revista Caros Amigos $^{16}$, o intelectual gramsciano recentemente falecido afirma que "democratização" seria mais apropriado que "democracia":

\begin{abstract}
Uma alteração que eu faria no velho artigo era colocar não democracia como valor universal, mas democratização como valor universal. Para mim a democracia é um processo, ela não se identifica com as formas institucionais que ela assume em determinados contextos históricos. A democratização é o processo de crescente socialização da política com maior participação na política, e, sobretudo, a socialização do poder político. Então, eu acredito que a plena socialização do poder político, ou seja, da democracia, só pode ocorrer no socialismo, porque numa sociedade capitalista sempre há déficit de cidadania. Em uma sociedade de classes, por mais que sejam universalizados os direitos, o exercício deles é limitado pela condição classista das pessoas. Neste sentido, para a plena realização da democracia, o autogoverno da sociedade só pode ser realizado no socialismo. Então, eu diria que sem democracia não há socialismo, e sem socialismo não há democracia. Acho que as duas coisas devem ser sublinhadas com igual ênfase.
\end{abstract}

Partindo da concepção de Coutinho de História/democracia como processos, e da afirmação de Alves (op. cit., p. 160), que diz que o "novo" não surge do acaso, mas "do solo de experiências construídas por gerações", entendemos que a construção de um presente socialmente igual, humanamente diferente e totalmente livre - como sentenciou Rosa Luxemburgo - não pode prescindir da análise cuidadosa das experiências humanas anteriormente forjadas

\footnotetext{
15 "Universal" como um horizonte ético-político; entendida como emancipação humana

16 Disponível em: http://carosamigos.terra.com.br/index/index.php/politica/2513-carlos-nelsoncoutinho-leia-entrevista-na-integra
}

TrabalhoNecessário - www.uff.br/trabalhonecessario; Ano 11, № 16/2013. 


\section{Trabalhonecessário}

Issn: 1808 - 799X

ano 11, no $16-2013$

pelos sujeitos coletivos, sendo a Modernidade ${ }^{17}$, um marco fundamental, como afirma o próprio Coutinho (op. cit., p. 36), ao defender o par preservação/radicalização do valor universal de inúmeras objetivações/formas de relacionamento social que formam a base institucional da democracia política. Diz ele (Ibidem):

A pluralidade de sujeitos políticos, a autonomia dos movimentos de massa (da sociedade civil) em relação ao Estado, a liberdade de organização. A legitimação da hegemonia através da obtenção do consenso majoritário: todas essas conquistas democráticas, portanto, continuam a ter pleno valor numa sociedade socialista.

Temos plena concordância com Coutinho, na afirmação anteriormente citada sobre o vínculo profundo entre democracia e socialismo. Entendemos que, a despeito dos sepultamentos constantes da História, das classes, das ideologias, e da profusão de discursos inaugurais, a educação continua sendo um espaço estratégico da luta de classes, uma dimensão fundamental da vida humana, cada vez mais fetichizada, mercantilizada e esterilizada em suas potencialidades emancipadoras pelo establishment burguês. A dualidade educacional de novo tipo (não mais educação apenas para alguns - como há décadas - mas para todos, sob formas/concepções distintas, de acordo com o "público"), de que falam Rummert, Algebaile e Ventura no texto em análise, produto direto da dualidade estrutural do modo de produção capitalista, enquanto expressão do antagonismo capital-trabalho (Rummert, Algebaile e Ventura, op. cit., p. 33), é exemplo explícito de que o capital-imperialismo continua compreendendo a educação como um

\footnotetext{
${ }^{17} \mathrm{Na}$ cronologia histórica clássica a Idade Moderna é o período compreendido entre os séculos XV e XVIII, iniciando em 1453, na tomada de Constantinopla (capital do Império Romano do Oriente) pelos turco-otomanos e terminando na Revolução Francesa, em 1789. Neste período, inúmeras transformações nos âmbitos cultural (Renascimento, lluminismo), político (surgimento dos Estados Nacionais, construção do Estado burguês, com as Revoluções em Inglaterra e França), religioso (Reforma Protestante), técnico-científico (Revolução Científica do XVII, com grandes descobertas/inovações na Física, Matemática, Biologia...), econômico (Grandes Navegações, Revolução Industrial) alteram profundamente a vida social no Ocidente, "dilatando" temporalmente a modernidade para além do século XVIII, chegando até o século XX.
} 


\section{Trabalhonecessário}

Issn: 1808 - 799X

ano 11, no $16-2013$

campo imprescindível na construção de consensos, no "encapsulamento ${ }^{18 "}$ dos trabalhadores e obviamente, na manutenção/crescimento de suas fontes de lucro.

Neste diminuto texto tentamos refletir sobre a relação hegemoniaeducação, sobre o capital-imperialismo e a teoria do desenvolvimento desigual e combinado, e finalmente, sobre a atuação dos intelectuais. Fica a sensação de incompletude devido à amplitude do tema (democracia e educação) e ao curto espaço para tais análises. Como nosso terceiro pilar analítico neste artigo foi "os intelectuais", gostaríamos de encerrar nossas considerações com mais algumas palavras sobre o tema, dentro do âmbito da educação.

Nas instituições e processos pedagógicos, diversos intelectuais desempenham funções distintas, desde as político-burocráticas (ao nível das políticas educacionais - sociedade política) até as técnico-formativas (ao nível molecular da escola - sociedade civil). Desempenhando estas últimas estão os educadores $^{19}$, que na concepção que defendemos, uma vez "conscientes" de sua origem e de seu vínculo de classe ("classe em si") e, sobretudo, comprometidos com os interesses desta classe ("classe para si"), podem agir como intelectuais orgânicos a esta classe. Se na leitura gramsciana, o intelectual é também um educador $^{20}$, o educador, "conectado com as lutas políticas" (SEMERARO, 2006, p. 133) de sua classe, pode desempenhar efetivamente a função de intelectual orgânico, mesmo em "tempos de pós-modernidade" (Ibidem).

A luta ao lado dos dominados, em tempos pós-modernos, coloca para os intelectuais orgânicos o necessário "retorno" a Gramsci - com quem "abrimos" as reflexões deste trabalho - no sentido de retomar o cerne de suas reflexões sobre os intelectuais, "aprendendo" com suas "recomendações" sobre o que cabe ao intelectual: lidar com a diversidade sem cair no relativismo", a "lutar contra os

\footnotetext{
${ }_{18}^{18}$ Termo usado por Fontes (2010, p. 11).

${ }^{19}$ Obviamente, muitos educadores desempenham funções de caráter político-burocráticas. No entanto, para nós, educadores são os profissionais que atuam diretamente na instituição educacional (seja ela a escola ou a universidade), sobretudo lecionando.

${ }^{20}$ Ver pág. 6.
}

TrabalhoNecessário - www.uff.br/trabalhonecessario; Ano 11, № 16/2013. 


\section{Trabalhonecessário}

Issn: 1808 - 799X

ano 11, no $16-2013$

dogmas sem deixar de buscar a verdade", a "respeitar a particularidade sem se pulverizar", a "construir a unidade sem transformá-la em uniformidade", e a "realizar a democracia popular contra os simulacros pós-modernos" (Ibidem, p. 149).

"Nunca como hoje o Brasil precisou tanto de novos intelectuais 'orgânicos", sentencia Semeraro. Sintonizados com esta perspectiva, e compreendendo, dialeticamente, os educadores como intelectuais (desenvolvedores da cultura, do conhecimento) e os intelectuais como educadores (compreendendo a ação pedagógica como fundamental para as lutas hegemônicas), defendemos que o professor (nunca isoladamente, mas numa práxis coletiva, que se some à outros agentes/lutas), consciente de seus vínculos de classe - fundamentais para Gramsci - e compromissado com os grupos subjugados, pode atuar como intelectual orgânico a esta classe, no interior da sociedade civil (na escola/universidade, poderosos aparelhos privados de hegemonia), construindo $o$ consenso em torno do projeto da classe da qual fazem parte/se identificam; enfrentando as concepções de mundo (ideologias) hegemônicas, expondo suas contradições e elaborando coletivamente outras ideologias; materializando a elevação moral e intelectual das massas, radicalizando os processos coletivos de democratização e finalmente, forjando, no limite, um movimento de contrahegemonia.

O atual estágio da luta de classes necessita de "novos professores", que assumam posições, se comprometam, "tomem partido", escolham seu "lado", "sintam" os anseios dos dominados, rompendo com a neutralidade cúmplice e o individualismo desmobilizador. Professores sintonizados com as dinâmicas históricas e as contradições do seu tempo, sendo críticos, cientistas e artífices de uma práxis transformadora, que radicalize a democracia, como frisava Carlos Nelson Coutinho. Intelectual-político, intelectual-popular, intelectual políticopedagógico. $\mathrm{O}$ "novo" intelectual de Marx e Gramsci faz-se mais do que nunca 


\section{Trabalhonecessário}

Issn: 1808 - 799X

ano 11, no $16-2013$

necessário nos dias de hoje, onde o pensamento crítico é desqualificado, a história como processo, a totalidade e a dialética são sepultadas e os projetos de emancipação humana ridicularizados.

\section{Referências}

ACANDA, Jorge Luis. Sociedade civil e hegemonia. Rio de Janeiro: Editora UFRJ, 2006.

ALVES, Claudia. Problemas da relação educação-cidadania na história brasileira. In: FELGUEIRAS, Margarida Louro \& VIEIRA, Carlos Eduardo (orgs.). Cultura escolar, migrações e cidadania. Porto: Sociedade Portuguesa de Ciências da Educação, 2010.

BUCI-GLUCKSMANN, Christinne. Gramsci e o estado. Rio de Janeiro: Paz e Terra, 1980.

CAMPIONE, Daniel. Hegemonia e contra-hegemonia na América Latina. In: COUTINHO, C. Nelson e TEIXEIRA, Andréa de P. (orgs). Ler Gramsci, entender a realidade. Rio de Janeiro: Civilização Brasileira, 2003, pp. 51-66.

COUTINHO, Carlos Nelson. A democracia como valor universal. Encontros com a Civilização Brasileira. Rio de Janeiro: Civilização Brasileira, v. 9, p. 33-47, 1979.

Gramsci: um estudo sobre seu pensamento político. Rio de Janeiro: Civilização Brasileira, 2007.

. Entrevista à Revista Caros Amigos, 2009.

Disponível em: http://carosamigos.terra.com.br/index/index.php/politica/2513carlos-nelson-coutinho-leia-entrevista-na-integra. Acesso em: 09 de dezembro de 2012.

COUTINHO, Eduardo Granja. Processos contra-hegemônicos na imprensa carioca, 1889/1930. In: Comunicação e contra-hegemonia: processos culturais e comunicacionais de contestação, pressão e resistência. Org. de Eduardo Granja Coutinho. Rio de Janeiro: Editora UFRJ, 2008, pp. 65-89.

TrabalhoNecessário - www.uff.br/trabalhonecessario; Ano 11, № 16/2013. 


\section{Trabalhonecessário}

Issn: 1808 - 799X

ano 11, no $16-2013$

DANTAS, Rodrigo. Ideologia, hegemonia e contra-hegemonia. In: Comunicação e contra-hegemonia: processos culturais e comunicacionais de contestação, pressão e resistência. Org. de Eduardo Granja Coutinho. Rio de Janeiro: Editora UFRJ, 2008, pp. 91-118.

EAGLETON, Terry. Ideologia: uma introdução. São Paulo: Editora da Universidade Estadual Paulista: Editora Boitempo, 1997.

FONTES, Virgínia. O Brasil e o capital-imperialismo: teoria e história. Rio de Janeiro: FIOCRUZ/UFRJ Editora.

GRAMSCI, Antonio. Cadernos do cárcere. Org. de Carlos Nelson Coutinho, Marco Aurélio Nogueira e Luiz Sérgio Henriques. Rio de Janeiro: Civilização Brasileira, 2006 (vol. 1), 2010 (vol. 2).

GRUPPI, Luciano. O conceito de hegemonia em Gramsci. Rio de Janeiro: Edições Graal, 1978.

HOBSBAWM, Eric. Como mudar o mundo: Marx e o marxismo, 1840-2011. São Paulo: Companhia das Letras, 2011.

JESUS, Antônio Tavares de. Educação e hegemonia no pensamento de Antonio Gramsci. São Paulo: Cortez, 1989.

LIGUORI, Guido. Roteiros para Gramsci. Rio de Janeiro: Editora UFRJ, 2007.

LÖWY, Michael. A teoria do desenvolvimento desigual e combinado. In: LÖWY, Michael \& BENSAID, Daniel. Marxismo, modernidade e utopia. São Paulo: Xamã, 2000.

MACCIOCCHI, Maria-Antonietta. A favor de Gramsci. Rio de Janeiro: Paz e Terra, 1977.

MÉSZÁROS, István. Para além do capital: rumo a uma teoria da transição. São Paulo: Boitempo, 2011.

MORAES, Denis de. A batalha da mídia: governos progressistas e políticas de comunicação na América Latina e outros ensaios. Rio de Janeiro: Pão e Rosas, 2009.

TrabalhoNecessário - www.uff.br/trabalhonecessario; Ano 11, № 16/2013. 


\section{Trabalhonecessário}

Issn: 1808 - 799X

ano 11, no $16-2013$

OLIVEIRA, Francisco de. Crítica à razão dualista: o ornitorrinco. São Paulo: Boitempo, 2003.

PORTELLI, Hugues. Gramsci e o bloco histórico. Rio de Janeiro: Paz e Terra, 1977.

SEMERARO, Giovanni. SEMERARO, Giovanni (org.). Filosofia e política na formação do educador. Aparecida, SP: Ideias \& Letras, 2004.

- Gramsci e os novos embates da filosofia da práxis.

Aparecida, SP: Ideias \& Letras, 2006.

. Saber-fazer filosofia: o pensamento moderno. Aparecida,

SP: Ideias \& Letras, 2011.

SOARES, Rosemary Dore. Gramsci, o estado e a escola. Ijuí: Ed. UNIJUÍ, 2000.

VIEIRA, Carlos Eduardo. Intelligentsia e intelectuais: sentidos, conceitos e possibilidades para a história intelectual. Revista Brasileira de História da Educação, Campinas: Autores Associados; SBHE, n. 16, p. 64-85, jan.abr. 2008. WILLIAMS, Raymond. Marxismo e literatura. Rio de Janeiro: Zahar, 1979.

Data de recebimento: 27/02/2013 Data de aprovação: 15/03/2013 